\title{
Pulmonary epithelioid hemangioendothelioma identified by computed tomography scan
}

\author{
Yoshiro Nakahara, Tatsuru Okamura, Kan Kato, Tsunekazu Hishima
}

\section{CASE REPORT}

Computed tomography (CT) scan showed bilateral, nodular, lung shadows in an asymptomatic 38-year-old female (Figure 1). Five nodules up to $10 \mathrm{~mm}$ each were identified in the right and left lungs. She was followedup for four months, during which the size and density of these shadows remained unaltered. The patient requested a definitive diagnosis and underwent a videoassisted thoracoscopic lung biopsy of two lesions in the right lower lobe (S6c, S9a). A histopathological examination showed vacuolated tumor cells, immunohistochemical staining of which was positive for the endothelial marker CD34. Electron microscopy identified Weibel-Palade bodies. These findings supported a diagnosis of pulmonary epithelioid hemangioendothelioma (PEH) (Figure 2). All other organs were free of abnormalities and the patient was remained under observation for two years without treatment or disease progression.

Yoshiro Nakahara ${ }^{1}$, Tatsuru Okamura ${ }^{1}$, Kan Kato ${ }^{2}$, Tsunekazu Hishima ${ }^{3}$

Affiliations: ${ }^{1}$ Department of Thoracic Oncology and Respiratory Medicine, Tokyo Metropolitan Cancer and Infectious Diseases Center Komagome Hospital, Tokyo, Japan; 2Department of Respiratory Medicine, Tokyo Kensei Hospital, Tokyo, Japan; ${ }^{3}$ Department of Pathology Tokyo Metropolitan Cancer and Infectious, Diseases Center, Komagome Hospital, Tokyo, Japan.

Corresponding Author: Yoshiro Nakahara, MD Department of Thoracic Oncology and Respiratory Medicine, Tokyo Metropolitan Cancer and Infectious Diseases Center Komagome Hospital, 3-18-22, Honkomagome, Bunkyo-ku, Tokyo 113-8677, Japan; Ph: +81- 3-3823-2101; Fax: +81- 3-3823-5433; E-mail: md100062@cick.jp

Received: 17 January 2013

Accepted: 25 April 2013

Published: 01 July 2013

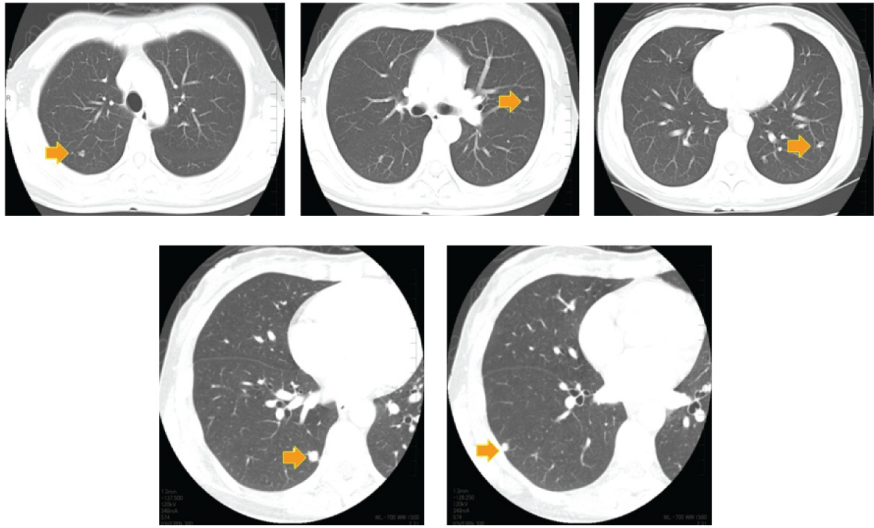

Figure 1: Computed tomography scan of chest. Bilateral, multiple, nodular, lung shadows range in size up to $10 \mathrm{~mm}$.

\section{DISCUSSION}

The grade of malignancy of rare, vascular pulmonary epithelioid hemangioendothelioma (PEH) is low to intermediate. These tumors can simultaneously or sequentially arise from the lungs, liver, bone and soft tissue, which renders multicentric tumor growth difficult to distinguish from primary lesions with metastasis to other tissues. Most patients with pulmonary epithelioid hemangioendothelioma (PEH) are female $(61-80 \%)$ and the median age is $36-50$ years, which is relatively younger than those with lung cancer. No specific symptoms are associated with $\mathrm{PEH}$, and $50-76 \%$ of patients are asymptomatic at the time the condition is detected by chest radiography. Our patient was also asymptomatic. Multiple pulmonary nodules, multiple pulmonary reticulonodular opacities, and diffuse infiltrative pleural thickening have been identified by computed tomography (CT) scan [1]. The most common feature of PEH on chest CT scan is the presence of multiple small discrete pulmonary nodules of up to $2 \mathrm{~cm}$ with well-defined margins in both lungs. However, most nodules are less than $1 \mathrm{~cm}$ in diameter. Dail et al. reviewed 20 patients and found that 20, $65 \%$ 


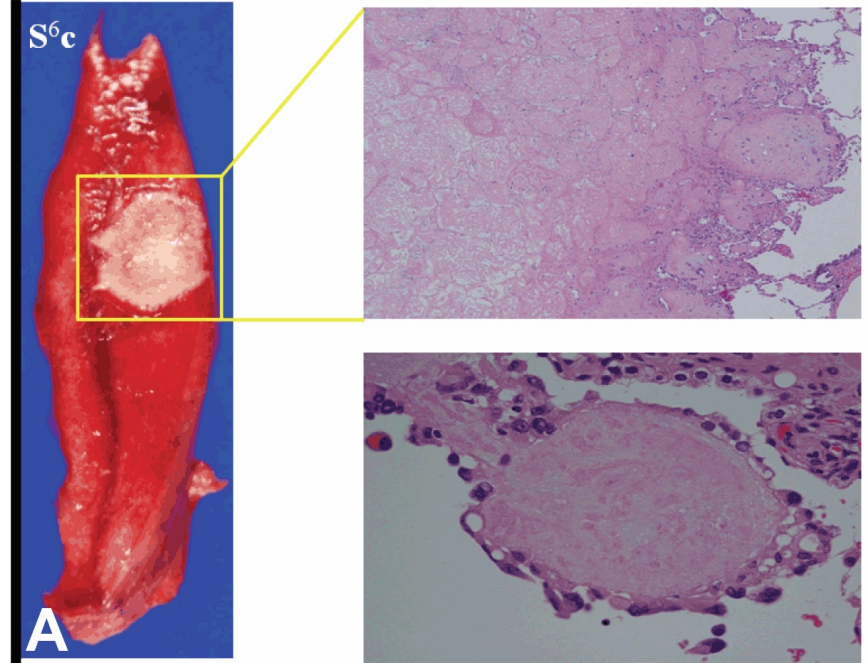

Hematoxylin-eosin(HE) stain

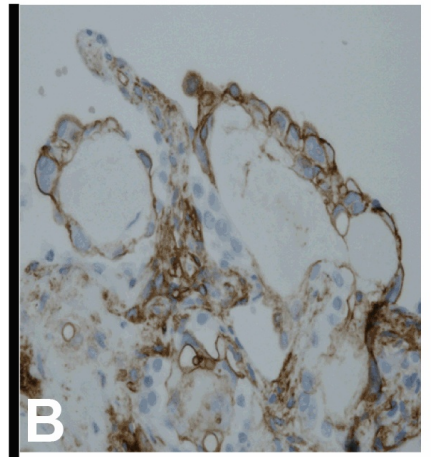

CD34(+)

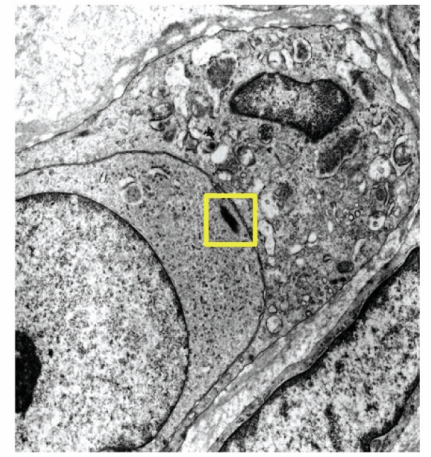

Electron microscopic examination Weibel-Palade Body
Figure 2: (A) Macroscopic appearance of the resected tumor (right lower lobe:S6c) showing whitish solid material. Vacuolated tumor cells were observed by Hematoxylin-eosin stain, (B) Immunohistochemical staining of tumor cells. Cells are positive for $\mathrm{CD}_{34}$, an endothelial marker. Electron microscopy shows Weibel-Palade bodies.

and $25 \%$ of them had $<10,10-20$ and $>20$ nodules, respctively [2]. On the other hand, Kitaichi et al. reported the CT scan of 18 patients, among whom four and 14 had unilateral and bilateral opacities, respectively. Two of the four with unilateral opacities had a single nodular opacity and one patient had pleural effusion without nodular opacities. All 14 patients with bilateral opacities had plural nodules, and one patient had pleural effusion. None of them had lymphadenopathy [3]. Surgery is an option for unilateral nodules, but a single effective treatment has been suggested for multiple or bilateral involvement [4]. Although PEH usually grows very slowly, it can metastasize to other organs. The 5-year survival rate is around $60 \%$. Respiratory failure (41.9\%) and metastasis (38.7\%) are common causes of death [4]. Hemorrhagic symptoms such as hemoptysis and pleural hemorrhagic effusion might indicate a poor prognosis [4].

\section{CONCLUSION}

Since multiple small lung nodules are likely be discovered more frequently with the increasing popularity of computed tomography (CT) screening, pulmonary epithelioid hemangioendothelioma (PEH) should be considered as a differential diagnosis.

$$
* * * * * * * * *
$$

Nakahara Y, Okamura T, Kato K, Hishima T. Pulmonary epithelioid hemangioendothelioma identified by computed tomography. International Journal of Case Reports and Images 2013;4(7):396-398.

$$
* * * * * * * * *
$$

doi:10.5348/ijcri-2013-07-340-14

\section{Author Contributions}

Yoshiro Nakahara - Substantial contributions to conception and design, Acquisition of data, Analysis and interpretation of data, Drafting the article, Revising it critically for important intellectual content, Final approval of the version to be published

Tatsuru Okamura - Substantial contributions to conception and design, Acquisition of data, Analysis and interpretation of data, Drafting the article, Revising it critically for important intellectual content, Final approval of the version to be published

Kan Kato - Substantial contributions to conception and design, Acquisition of data, Analysis and interpretation of data, Drafting the article, Revising it critically for important intellectual content, Final approval of the version to be published

Tsunekazu Hishima - Substantial contributions to conception and design, Acquisition of data, Analysis and interpretation of data, Drafting the article, Revising it critically for important intellectual content, Final approval of the version to be published

\section{Guarantor}

The corresponding author is the guarantor of submission.

\section{Conflict of Interest}

Authors declare no conflict of interest.

\section{Copyright}

(C) Yoshiro Nakahara et al. 2013; This article is distributed under the terms of Creative Commons attribution 3.0 License which permits unrestricted use, distribution and reproduction in any means provided the original authors and original publisher are properly credited. (Please see www.ijcasereportsandimages.com /copyright-policy.php for more information.) 


\section{REFERENCES}

1. Kim EY, Kim TS, Han J, Choi JY, Kwon OJ, Kim J. Thoracic epithelioid hemangioendothelioma: imaging and pathologic features. Acta Radiol 2011;52(2):161-6.

2. Dail DH, Liebow AA, Gmelich JT, et al. Intravascular bronchiolar, and alveolar tumor of the lung(IVBAT).An analysis of twenty cases of a peculiar sclerosing endothelial tumor. Cancer 1983;51(3):452-64.

3. Kitaichi M, Nagai S, Nishimura K, et al. Pulmonary epithelioid hemangioendothelioma in 21 patients, including three with partial spontaneous regression. Eur Respir J 1998;12(1):89-6.

4. Bagan P, Hassan M, Le Pimpec Barthes F, et al. Prognostic factors and surgical indications of pulmonary epithelioid hemangioendothelioma: a review of the literature. Ann Thorac Surg 2006;82(6):2010-3.

Access full text article on other devices

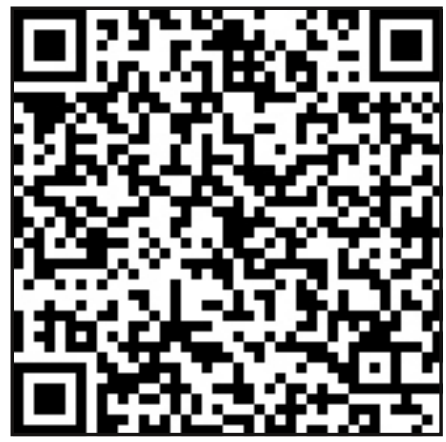

Access PDF of article on other devices

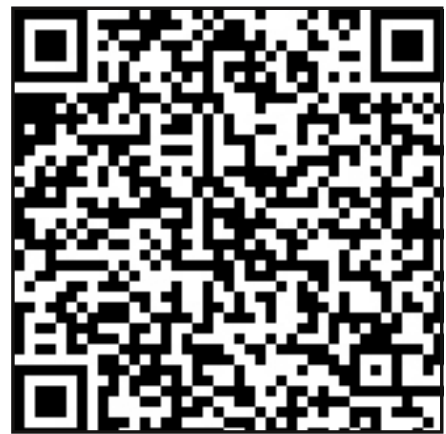

